point supports this view. If this is so, the balance between thickness of walls and arterial pressure is maintained; the one increases in the same proportion as the other, and albuminuria does not ensue. Very different is this from the case of acute Bright's disease, where the arterial pressure rises rapidly or suddenly before the vessels have time to thicken, and out comes the albumin. So, at any time, if in chronic Bright's disease an exacerbation of the disease occurs, the blood-pressure rapidly rises and albuminuria ensues. Probably in this condition the albumin is always much nearer transudation-point than in the healthy kidney, and therefore slight variations, produced by many causes, suffice to bring it through. Albuminuria is therefore frequently seen in chronic Bright's disease, and so comes to be called a symptom of it, but it is not an essential one; the disease may, and commonly does, exist without it; it is only due to an exacerbation of the disease, or, in other words, an approach to its acute form. This may be said to be mere carping at words, but it is not the recognition of this fact, we shall see hereafter, will throw light on the true nature of the disease and its identification.

It remains to make a few remarks on the history of high arterial tension and its recognition. The earliest writers on the subject have always recognised the occurrence of hypertrophy of the heart and thickening of the arteries, together with a hard pulse, in chronic Bright's disease. Dr. Burdon-Sanderson and Dr. Sibson appear to have been the first, as far as $I$ can discover, to demonstrate by means of the sphygmograph the high arterial tension which exists in this condition. Dr. Broadbent proved that the hard pulse and the high tension were not mere results of the thickened arteries, but were functional conditions due to the conditions of the circulation and to some impediment in the blood-flow. He proved that they were not the essential result of the thickening of the arteries, by demonstrating the softening of the pulse by the use of nitrite of amyl, produced in a man suffering from chronic Bright's disease and with very high arterial tension; the tracings showed that by the use of the drug his arteries were relaxed, the arterial tension changed from very high to comparatively low, and the pulse became large, soft, and dicrotic. This experiment was of the utmost importance, because it went far towards proving that the high arterial tension was a functional condition and the cause of the thickening of the vessels and the hypertrophy of the heart, instead of being caused by them.

Thus far our knowledge of this condition was limited to chronic Bright's disease. Dr. Galabin was the first to definitely record the fact that the same condition prevailed in acute Bright's disease, in his most admirable thesis " On the connexion of Bright's Disease with changes in the Vascular System" (1873). In the paper already alluded to, published in the Transactions of the Medico-Chirurgical Society, I demonstrated that the condition of high arterial tension was the precursor of any other symptom; that it occurred as the immediate result of the condition of bloodpoisoning, which produces or tends to produce Bright's disease; that if cheeked on its first appearance no symptoms of kidney disease ensued, but if neglected it was invariably followed by them. I made my observations chiefly on the acute form of the disease, as seen following scarlet fever, but I proved that it held good for other and more chronic forms, that the high tension resulted also from the poisoned blood in pregnancy, lead-poisoning, gout, alcohol, and other well-known causes of Bright's disease, and that it was in all cases the great guide to treatment; and, moreover, I argued from these facts that it was a probable indication of the existence of arterio-capillary fibrosis.

Dr. Broadbent has long recognised the great importance of this condition of arterial tension, and in some most valu able clinical lectures on the "Pulse," described the pulse of high arterial tension amongst others, and has insisted on the extreme importance of its recognifion as an assistance to diagnosis, prognosis, and therapeutics. In these lectures he narrates three cases in which he has foretold attacks of cerebral hiemorrhage by the pulse, predictions which he saw in each case fatally fulfilled. I believe these are by no means the only cases in which he has been able to make, and has seen verified, such predictions. In the following year Dr. Handfield Jones pointed out the ralue of the sphygmograph in diagnosing the condi-

13 THE LANCET, Sept. 25th, Oct. 16th, 23rd, and Dec. 25th, 1875. tion known as arterio-capillary fibrosis, ${ }^{14}$ quoting several cases in which he had diagnosed the disease by this means, when no other symptoms were present. I also gave some further examples ${ }^{15}$ of cases in which I surmised the existence of this disease from the state of the pulse, and insisted on the importance of this symptom, in some remarks made before the Pathological Society.

(To be continued.)

\section{ON EXTERNAL URETHROTOMY.}

BY G. B. MORGAN,

SENIOR SURGEON TO THE SUNDERLAND INFIRMARY.

THE external division of the male urethra may either be done as an operation considered to be expedient or it may be imperatively demanded to save life.

In $1844 \mathrm{Mr}$. Syme communicated to the Edinburgh Medical Journal a paper in which he described a form of urethral stricture in which, although a very small instru. ment may be passed through it, no progress is made in getting it dilated. Constitutional disturbance, with rigors and suppuration, follow the introduction of an instrument, or it is found that after dilatation the dense tissue recontracts; and the patient, after weelss of treatment, is still suffering as at first. In these cases Mr. Syme proposed to divide the stricture through the perineum, having first introduced a slender grooved staff as a guide upon which to cut. This operation, in suitable cases, and with sedulous care afterwards, gives very satisfactory results, and is not difficult of performance. But sometimes we meet with cases where it is impossible to pass the very smallest instrument, where the urine is distilled drop by drop, either through the urethra or some collateral fistula, and even that only after the most agonising expulsive efforts, where the swollen face, protruding eyeball, and conjunctiva stained with blood, show how violent and how sustained the effort has been, while during sleep the stinking urine drains from the overdis. tended bladder, soaking the bed, and making life miserable. Early in these cases, which are often cases of traumatic stricture, extravasation sometimes occurs; but later, when they have become chronic, it is wonderful the amount of hydraulic pressure which the tissues become capable of sustaining.

Now it is in these cases that operative interference is so imperatively demanded, and is at the same time so difficult of performance. If you cannot get a guide into the bladder, you must dissect out the urethra behind the stricture without a guide, and no one who has not himself done the opera. tion can estimate its great difficulty. Sir Henry Thompson says: "In reference to perineal section, or the operation without a guide, the best that can be said of it is that it is a hazardous proceeding. No surgeon should entertain the idea of performing it except after thoroughly assuring himself that the stricture cannot be rendered permeable to instruments, and so made amenable to treatment in some other way. In a few cases the operation is performed successfully, but in most there can be little doubt that the ronte of the stricture itself is not followed, and that the knifo makes a new channel through adjacent and often unsound tissues, very inadequate to perform subsequently the function of a urethra; and in many instances the attempt to make a channel to the bladder has wholly failed, and the patient has been removed from the table unrelieved, and in not a few cases the result has been fatal."

Mr. John Coulson was, I believe, the first to devise the following operation, which is now generally practised. It has been improved upon by Dr. Gouley, of New York, and attention has been drawn to it by Mr. Teevan :-The patient having had the rectum cleared, and the perinenm shaved, is to be put into the lithotomy position, and placed under chloroform. A straight staff, with a groove running to within half an inch of the end, and terminating in a button, is passed down to the stricture. The urethra is opened upon this groove, not upon the point of the staff. The staff is then

14 "Some Experience of the Sphygmograph in Medicine," THE LANCET, Feb. 19th, 26th. 1876 .

15 THE LANCET, Aug. 18th, 1877 
made to protrude, and the button hitched in the upper end of the wound, so as to enable the assistant to hold up the urethra by it. The edges of the opened canal are held apart by toothed forceps, and the operator proceeds to search in the cul de sac for the mouth of the stricture, by means of very fine whalebone probes. These should be olive-tipped, but there is difficulty in getting them properly made in England. Having found a passage, a fine silver tube is passed over the whalebone, and if the whalebone has been in the bladder urine will flow through the tube. The stricture is then divided upwards with a tenotome, directed by the slit in the tube, and then one half of an elastic catheter is passed into the bladder upon the tube, and the other half having been passed through the meatus, the two parts of the instrument are united by a screw-joint, and the patient is removed to bed.

The advantages claimed for this operation are:-l. The greater chance of finding an entrance to the stricture with a fine olive-tipped bougie, applied close to the face of the stricture. 2. The demonstrating that the bougie is really in the bladder, by passing over it a fine silver tube, and drawing off the urine, and so saving the mortification of laying open a false passage. 3. The metal tube serves as a guide for the passage of a catheter over it. 4. Diminishing the risk by dividing the stricture subcutaneously, instead of enlarging the original wound.

No doubt these advantages are great, and the operation should always be attempted in preference to perineal section, but the two cases which $I$ now proceed to narrate show that sometimes it is impossible to find a passage through the stricture, and in one case the patient was saved by perineal section, while in the other success was obtained by utilising a fistulous opening.

Mr. M- a - aged forty-three, formerly a mariner, a thick-set and strongly-built man. Twenty years ago he fell on board ship and came astride upon a hatchway, the sharp edge striking the perineum with great force. He passed water with great difficulty for some days afterwards, and lost a good deal of blood. The difficulty in making water abated, and he returned to work, but four or five months after he was obliged to enter, the Dreadnought Hospital with tight stricture. Here an instrument was passed and left in the bladder, but two days afterwards extravasation of urine occurred, requiring free incisions for its relief. Some of these incisions have continued as fistulæ ever since, and the urine has come through them as well as through the proper channel. This latter, however, has become less and less, and four years ago, when he was first seen by me, only a very slight moisture was perceptible at the meatus when he attempted to pass water. His state then-January, 1874was one of great suffering. Sometimes he would strain for hours, until his face was swollen and livid and the eyes sufiused with blood, before a few drops of stinking urine would exude from some of the fistulous openings and give him temporary relief. The perineum was riddled with openings and scarred with cicatrices; on each side of the anus were the marks of deep incisions; on the inner surface of the right thigh were two openings, and three more existed between the anus and scrotum. Marital intercourse had become so painful that it was unbearable. The prostate could be felt much enlarged.

Patient and prolonged attempts were made to pass an instrument through the stricture, but without success; and at this time nothing more was done than administering opium occasionally and directing the frequent use of the hip-bath.

During the next two years and a half he dragged on a very miserable existence, confined to his room and often to his bed, for he found that the slightest cold made all his sufferings worse. On two occasions during this time it was found necessary to tap the bladder through the rectum with an aspirator needle, to relieve his intolerable agony.

In November, 1876, his sufferings had become so great that he became most urgent in his entreaties for something to be done for him; and, having explained to him the great risk of the operation, I consented to attempt his relief.

He was prepared as for lithotomy, and a director passed down to the stricture. Upon this the urethra was opened, and most patient attempts made to find any passage through it. These attempts were continued for more than two hours, so unwilling was I to resort to perineal section-that is, dissecting out the urethra beyond the stricture without a guide for in his case this operation, always uncertain and difficult, would have been almost impossible, from the seamed and scarred state of the perineum. Having failed to enter the stricture, $I$ determined to try if access to the bladder could not be obtained through any of the fistulæ, and, to my great relief, I was at length able to pass the whalebone guide through an opening to the left of the raphe and along a tortuous passage into the bladder; upon it I passed the silver director, and freely divided the tissues, so that a fullsized instrument could be passed into the bladder. At the time I contemplated a further operation when he had recovered from the prolonged one, but I have found so much reason to be satisfied with what we have gained that $I$ am only too thankful to leave well enough alone. The relief is complete to all the symptoms, and, with the exception of the pain which the passing of some small stones through the new channel has caused, he has had no suffering since the operation. When I felt with the probe that these stones were stuck in the passage, I introduced a sea-tangle tent and left it for a few hours, and when it was withdrawn the stones came with the gush of urine. Coition is no longer painful, the semen coming through the new channel. The character of the urine is no longer bloody and ammoniacal, and he has perfect control over the bladder. Once a fortnight a bougie is passed, as the skin opening has a tendency to close. From the bedridden condition of a confirmed in. valid, whose every waking hour was one of suffering, he is restored to his business and to the enjoyment of his life.

Mr. T_ aged sixty, a master mariner, came to me on July 16th, 1877, complaining of incontinence of urine, his clothes in the day and his bed in the night being soaked; while he had the greatest difficulty in micturition. His constant straining had produced hernia of the bowel on the left side. He had been a man of somewhat dissipated habits, and stated that about thirty years ago he remembered having an attack of complete retention, which was only relieved with great difficulty by the passage of an instrument on the third day. Since then there had never been complete retention, but year by year the stream had become smaller, and within the last two years the urine had been voided drop by drop, and stillicidium urinæ had become constant. The character of the secretion was ammoniacal and mixed with glairy mucus. The glans penis had several scars upon it, and one cicatrix occupied the site of the meatus, which it had so narrowed that a No. 5 entered with difficulty; beyond this the urethra was narrowed at two points-one about two inches within, and again in front of the membranous portion of the urethra.

He was confined to bed, and placed upon milk diet, with small doses of opium; and day after day attempts were made to penetrate the stricture, but without any success. His condition improved somewhat from the rest and restricted diet, and the stillicidium was greatly lessened as the urine became less acrid; but it was found impossible to enter the bladder. An attempt was made by passing potassa fusa down to the face of the stricture to overcome it; this, however, not only failed, but seemed to increase the difficulty of micturition.

On Aug. 30th he was placed under chloroform, and the operation of $\mathrm{Mr}$. Coulson attempted. He was prepared as for lithotomy, the director passed to the stricture, the urethra opened upon it, and the mouth of the stricture patiently sought for with the whalebone bougies and also with fine silver probes. For two hours on this, the first day, and for a similar time on the day following, these attempts were continued, and were at length with great reluctance abandoned. A day was allowed to intervene, and a third time he was placed under chloroform, and the urethra carefully dissected out, and after some difficulty opened behind the stricture. The latter was then laid open, and the pointed catheter passed into the bladder and out through the meatus. That was on Sept. 2nd. For a few days a catheter was passed daily, then every second day, then once a week, and now (Oct. 31st) the wound is healed, and he passes for himself a flexible bougie, and micturates in a full stream without pain or difficulty. To use his own words, he is a new man, and is comfortable for the first time for twenty years.

Donations etc. To Medical Charitifis. - The York County Hospital, and the York Dispensary have each received $£ 455$ 2 $2 s$. $6 d$. under the will of Mr. George Wright, of York. The Sea-Bathing Infirmary, Margate, has become entitled to $£ 100$ under the will of Mrs. Charlotte Anne Hodgson, of Oakside, Surbiton. Her Majesty has given 100 guineas to the Queen's Hospital, Birmingham. 